\title{
In vivo inhibitory effect of suberoylanilide hydroxamic acid combined with sorafenib on human hepatocellular carcinoma cells
}

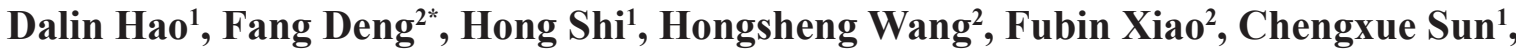 \\ Yansong $\mathrm{Xu}^{\oplus 2}$, Peng $\mathrm{Li}^{2}$
}

\begin{abstract}
${ }^{1}$ Department of Infection and Hepatology, the Affiliated Hospital of Beihua University, Jilin, China, ${ }^{2}$ Department of Hepatobiliary and Pancreatic Surgery, the Affiliated Hospital of Beihua University, Jilin, China
\end{abstract}

\begin{abstract}
The present study aimed to investigate the in vivo inhibitory effect of histone deacetylase inhibitor suberoylanilide hydroxamic acid (SAHA) combined with sorafenib on human hepatocellular carcinoma HCCLM3 cells. The nude mice transplanted with HCCLM3 cells were randomly divided into control, SAHA, sorafenib and SAHA+sorafenib groups. The nude mice in the later 3 groups were intragastrically administrated with SAHA $\left(10 \mathrm{mg} \cdot \mathrm{kg}^{-1} \cdot \mathrm{day}^{-1}\right)$, sorafenib $\left(10 \mathrm{mg} \cdot \mathrm{kg}^{-1} \cdot \mathrm{day}^{-1}\right)$ and SAHA $\left(10 \mathrm{mg} \cdot \mathrm{kg}^{-1} \cdot \mathrm{day}^{-1}\right)$ combined with sorafenib $\left(10 \mathrm{mg} \cdot \mathrm{kg}^{-1} \cdot \mathrm{day}^{-1}\right)$, respectively, for successive 20 days. Finally, the inhibition rate of tumor was measured. The expressions of MEK1/2, p-ERK1/2, Cyclin D1, Bcl-2, Bax, p53, MMP2, MMP-9 and uPA in tumor tissues were determined. Results showed that, compared with SAHA and Sorafenib groups, in SAHA+sorafenib groups the inhibition rate of tumor was significantly increased (P $<0.05$ ), the expression levels of MEK1/2, p-ERK1/2, Cyclin D1, Bcl-2, MMP-2 and MMP-9 and uPA protein in tumor tissues were significantly decreased, respectively $(\mathrm{P}<0.05)$, and the expression levels of Bax and $\mathrm{p} 53$ protein were significantly increased, respectively $(\mathrm{P}<0.05)$. In conclusion, compared with single drug, SAHA combined with sorafenib can enhance the inhibitory effects on HCCLM3 xenografts in nude mice.
\end{abstract}

Keywords: Suberoylanilide hydroxamic acid. HCCLM3. Inhibitory. In vivo.

\section{INTRODUCTION}

Hepatocellular carcinoma (HCC) is one of the most common malignant tumors around the world, especially in Asia, Africa and southern Europe. HCC has high malignancy and short survival time of patients, and the 5 year survival rate of patients with HCC is about 3\%$5 \%$ (Bruix, Reig, Sherman, 2016). Surgery is the main method for treating HCC. However, due to the insidious onset and rapid progress, $\mathrm{HCC}$ has no atypical symptom at the early stage. Once HCC occurs, it has already entered the late stage, and has usually lost the chance of radical surgical treatment. In addition, the low surgicalresection rate and high recurrence and metastasis rates are also the main factors affecting the clinical treatment efficacy of HCC (Koniaris et al., 2011). Although the synergetic chemoradiotherapy, liver transplantation and interventional therapy are often used for treating HCC,

\footnotetext{
*Correspondence: F. Deng. Department of Hepatobiliary and Pancreatic Surgery, Affiliated Hospital of Beihua University, No. 12 middle Jiefang Road, Jilin 132011, China. E-mail: deng_fang1@yeah.net
}

the therapy effect is not ideal. Furthermore, the patients with advanced HCC are often accompanied by basic diseases such as liver dysfunction and liver cirrhosis, which seriously restricts the further application of cytotoxic chemotherapeutic drugs (Lee et al., 2012). Therefore, seeking more effective new strategies has become the focus of the treatment of HCC. Histone deacetylase inhibitors (HDACIs) are the new epigenetic modification anticancer agents. They can regulate the abnormal acetylation of histone in chromatin of tumor cells by epigenetic modification and regulate the gene transcription, thus inhibiting the occurrence and development of tumors. It has been proved that, HDACIs have inhibitory effects on a variety of tumor cells. The application of HDACIs may be an ideal choice for antitumor treatment (Bao et al., 2016; Shen, Orillion, Pili, 2016). This study established the nude mice xenograft model of human HCC HCCLM3 cells, and aimed to investigate the effects of HDACI suberoylanilide hydroxamic acid (SAHA) combined with sorafenib on the tumor growth and the related mechanism. 


\section{MATERIAL AND METHODS}

\section{Establishment of HCCLM3 xenograft model in nude mice}

HCCLM3 cells (Shanghai Cell Resource Center of the Chinese Academy of Sciences, Shanghai, China) were cultured, and the cells in logarithmic growth phase were collected to prepare the single cell suspension $\left(5 \times 10^{6} \mathrm{cell} \mathrm{s} / \mathrm{ml}\right)$. Two hundred microlitre of cell suspension was inoculated at the right forelimb oxter of nude mice (male, 4-6 weeks old, 20-24g; Shanghai Silaike Experimental Animal Co., Ltd., Shanghai, China). The mice were routinely reared for one week.

\section{Animal grouping and treatment}

Forty modeled nude mice were randomly divided into control, SAHA, sorafenib and SAHA+sorafenib groups, 10 mice in each group. The nude mice in the later 3 groups were intragastrically administrated with SAHA (10 $\mathrm{mg} \cdot \mathrm{kg}^{-1} \cdot$ day $^{-1}$; Santa Cruz Biotechnology Co., Ltd., CA, USA), sorafenib $\left(10 \mathrm{mg} \cdot \mathrm{kg}^{-1} \cdot \mathrm{day}^{-1}\right.$; Bayer AG, Leverkusen, Germany), and SAHA (10 mg $\left.\mathrm{kg}^{-1} \cdot \mathrm{day}^{-1}\right)$ combined with sorafenib $\left(10 \mathrm{mg} \cdot \mathrm{kg}^{-1} \cdot \mathrm{day}^{-1}\right)$, respectively. The doses were based on the pre-experiments. The nude mice in the control group were given with the same volume of normal saline. The administration was continued for 20 days. The status and activities of nude mice were observed daily.

\section{Determination of nude mice body weight and growth of tumor}

At the end of experiment, the body weight of nude mice was measured using electronic balance. Then, all nude mice were executed by cervical dislocation. The xenograft blocks were stripped, and were weighed. The inhibition rate of tumor was calculated as follows: inhibition rate $(\%)=(1-$ xenograft weight in treatment group / xenograft weight in control group) $\times 100 \%$.

\section{Determination of protein expressions of tumor proliferation, apoptosis and invasion related signal molecules in tumor tissue}

Tumor tissue was homogenized, and the protein was extracted. The expressions of tumor proliferation-related proteins including mitogen-activated protein kinase kinase 1/2 (MEK1/2), phosphorylated extracellular regulated protein kinase 1/2 (p-ERK1/2) and Cyclin D1, apoptosisrelated proteins including B-cell lymphoma-2 (Bcl-2),
Bcl-2 associated X protein (Bax) and p53, invasion-related proteins including matrix metalloproteinase (MMP)-2, MMP-9 and urokinase type plasminogen activator (uPA) in tumor tissues were determined using western blot assays. The procedures were according to the instruction of kits.

\section{Statistical analysis}

All statistical analysis was carried out using SPSS 22.0 software (SPSS Inc., Chicago, IL, USA). Each experiment was repeated for three times, and the data were presented as mean $\pm \mathrm{SD}$. The comparison was performed among different groups using one way single-factor analysis followed by Tukey's post hoc test. $\mathrm{P}<0.05$ was considered as statistically significant.

\section{RESULTS}

\section{Growth of nude mice}

During the whole experiment, the nude mice in each group acted freely and responded sensitively, with normal eating and drinking. No subcutaneous bleeding spot was found, and no nude mice died. At the end of the experiment, no obvious pleural or celiac effusion was found in each group. There was no significant different in initial weight of nude mice among four groups $(\mathrm{P}>0.05)$. Compared with the initial weight, the final weigh of nude mice was increased in each group. In addition, the final weight in SAHA, sorafenib and SAHA+sorafenib group was significantly lower than that in control group, respectively $(\mathrm{P}<0.05)$, and that in SAHA+sorafenib group was significantly lower than that in SAHA and sorafenib group, respectively $(\mathrm{P}<0.05)$ (Table I).

TABLE I - Body weight of nude mice

\begin{tabular}{lcc}
\hline Group & Initial weight $(\mathrm{g})$ & Final weigh $(\mathrm{g})$ \\
\hline Control & $22.31 \pm 0.74$ & $24.17 \pm 0.55$ \\
SAHA & $21.82 \pm 0.66$ & $23.34 \pm 1.08^{\mathrm{a}}$ \\
Sorafenib & $22.34 \pm 0.41$ & $23.03 \pm 0.62^{\mathrm{a}}$ \\
SAHA + sorafenib & $21.71 \pm 0.52$ & $22.26 \pm 0.66^{\mathrm{abc}}$ \\
\hline${ }^{\mathrm{a}} \mathrm{P}<0.05$ compared with control group; ${ }^{\mathrm{b}} \mathrm{P}<0.05$ compared with \\
SAHA group; ${ }^{\mathrm{P}}<0.05$ compared with Sorafenib group. SAHA, \\
suberoylanilide hydroxamic acid.
\end{tabular}

\section{Growth of HCCLM3 xenograft in nude mice}

At the end of the experiment, the weight of HCCLM3 xenograft in sorafenib and SAHA+sorafenib 
groups was significantly lower than that in control group, respectively $(\mathrm{P}<0.05)$, and that in SAHA+sorafenib group was significantly lower than that in SAHA and sorafenib groups, respectively $(\mathrm{P}<0.05)$. In addition, the inhibition rate of tumor in SAHA+sorafenib groups was significantly higher than that in SAHA and sorafenib group, respectively $(\mathrm{P}<0.05)$ (Table II).

TABLE II - Growth of HCCLM3 xenograft in nude mice

\begin{tabular}{lcc}
\hline Group & $\begin{array}{c}\text { Xenograft weight } \\
(\mathbf{g})\end{array}$ & $\begin{array}{c}\text { Inhibition rate } \\
(\mathbf{\%})\end{array}$ \\
\hline Control & $2.38 \pm 0.62$ & - \\
SAHA & $2.01 \pm 0.52$ & $15.23 \pm 3.38$ \\
Sorafenib & $1.76 \pm 0.41^{\mathrm{a}}$ & $26.03 \pm 4.12^{\mathrm{b}}$ \\
SAHA+sorafenib & $1.34 \pm 0.33^{\mathrm{abc}}$ & $42.88 \pm 7.26^{\mathrm{bc}}$ \\
\hline
\end{tabular}

${ }^{a} \mathrm{P}<0.05$ compared with control group; ${ }^{\mathrm{b}} \mathrm{P}<0.05$ compared with SAHA group; ${ }^{\mathrm{P}}<0.05$ compared with Sorafenib group. SAHA, suberoylanilide hydroxamic acid.

\section{Expression of MEK1/2, p-ERK1/2 and Cyclin D1 protein in xenograft tissue}

As shown in Table III, compared with control group, the expression levels of MEK1/2 protein in SAHA, sorafenib and SAHA+sorafenib groups, $\mathrm{p}$-ERK1/2 protein in sorafenib and SAHA+sorafenib groups and Cyclin D1 protein in sorafenib and SAHA+sorafenib groups were significantly decreased, respectively $(\mathrm{P}<0.05)$. Compared with sorafenib group, the expression levels of MEK1/2, $\mathrm{p}$-ERK1/2 and Cyclin D1 protein in SAHA+sorafenib group were significantly decreased, respectively $(\mathrm{P}<0.05)$.

\section{Expression of $\mathrm{BCl}-2$, Bax and p53 protein in xenograft tissue}

Table IV showed that, compared with control group, the expression levels of Bcl-2 and Bax protein in xenograft tissue in SAHA, sorafenib and SAHA+sorafenib groups were significantly decreased, respectively $(\mathrm{P}<0.05)$, and the expression level of $\mathrm{p} 53$ protein in sorafenib and $\mathrm{SAHA}+$ sorafenib groups were significantly increased, respectively $(\mathrm{P}<0.05)$. In addition, the expression level of Bcl-2 protein in SAHA+sorafenib group was significantly lower than that in SAHA and sorafenib groups, respectively $(\mathrm{P}<0.05)$, and the expression levels of Bax and 53 protein in SAHA+sorafenib group were significantly higher than those in SAHA and sorafenib groups, respectively $(\mathrm{P}<0.05)$.

\section{Expression of MMP-2 and MMP-9 and uPA protein in xenograft tissue}

Compared with control group, the expression levels of MMP-2 and uPA protein in xenograft tissue

TABLE III - Expression of MEK1/2, p-ERK1/2 and Cyclin D1 protein in xenograft tissue (relative to $\beta$-actin)

\begin{tabular}{lccc}
\hline Group & MEK1/2 & p-ERK1/2 & Cyclin D1 \\
\hline Control & $0.87 \pm 0.16$ & $1.12 \pm 0.16$ & $1.23 \pm 0.26$ \\
SAHA & $0.67 \pm 0.11^{\mathrm{a}}$ & $0.95 \pm 0.21$ & $1.12 \pm 0.21$ \\
Sorafenib & $0.51 \pm 0.09^{\mathrm{ab}}$ & $0.61 \pm 0.08^{\mathrm{ab}}$ & $0.84 \pm 0.08^{\mathrm{ab}}$ \\
SAHA+sorafenib & $0.34 \pm 0.08^{\mathrm{abc}}$ & $0.42 \pm 0.06^{\mathrm{abc}}$ & $0.76 \pm 0.05^{\mathrm{abc}}$ \\
\hline
\end{tabular}

a $\mathrm{P}<0.05$ compared with control group; ${ }^{\mathrm{b}} \mathrm{P}<0.05$ compared with SAHA group; ${ }^{\mathrm{c}} \mathrm{P}<0.05$ compared with Sorafenib group. SAHA, suberoylanilide hydroxamic acid; MEK1/2, mitogen-activated protein kinase kinase 1/2; p-ERK1/2, phosphorylated extracellular regulated protein kinase $1 / 2$.

TABLE IV - Expression of Bcl-2, Bax and p53 protein in xenograft tissue (relative to $\beta$-actin)

\begin{tabular}{|c|c|c|c|}
\hline Group & Bcl-2/ק-actin & 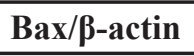 & p53/ß-actin \\
\hline Control & $0.82 \pm 0.21$ & $0.12 \pm 0.05$ & $1.01 \pm 0.18$ \\
\hline SAHA & $0.71 \pm 0.24^{\mathrm{a}}$ & $0.21 \pm 0.08^{\mathrm{a}}$ & $1.15 \pm 0.19$ \\
\hline Sorafenib & $0.36 \pm 0.15^{\mathrm{ab}}$ & $0.46 \pm 0.19^{\mathrm{ab}}$ & $1.34 \pm 0.28^{\mathrm{a}}$ \\
\hline SAHA+sorafenib & $0.23 \pm 0.04^{\mathrm{abc}}$ & $0.89 \pm 0.22^{\mathrm{abc}}$ & $1.56 \pm 0.21^{\mathrm{abc}}$ \\
\hline
\end{tabular}

a $\mathrm{P}<0.05$ compared with control group; ${ }^{\mathrm{P}} \mathrm{P}<0.05$ compared with SAHA group; ${ }^{\mathrm{c}} \mathrm{P}<0.05$ compared with sorafenib group. SAHA, suberoylanilide hydroxamic acid; Bcl-2, B-cell lymphoma-2; Bax, Bcl-2 assaciated X protein. 
Dalin H., Fang D., Hong S., Hongsheng W., Fubin X., Chengxue S., Yansong X., Peng L.

TABLE V - Expression of MMP-2 and MMP-9 and UPA protein in xenograft tissue (relative to $\beta$-actin)

\begin{tabular}{lccc}
\hline Group & MMP-2 & MMP-9 & uPA \\
\hline Control & $0.87 \pm 0.36$ & $1.12 \pm 0.16$ & $0.67 \pm 0.22$ \\
SAHA & $0.67 \pm 0.11$ & $0.94 \pm 0.11^{\mathrm{a}}$ & $0.54 \pm 0.19$ \\
Sorafenib & $0.51 \pm 0.09^{\mathrm{ab}}$ & $0.61 \pm 0.08^{\mathrm{ab}}$ & $0.43 \pm 0.13^{\mathrm{a}}$ \\
SAHA+sorafenib & $0.41 \pm 0.08^{\mathrm{abc}}$ & $0.42 \pm 0.06^{\mathrm{abc}}$ & $0.15 \pm 0.04^{\mathrm{abc}}$ \\
\hline
\end{tabular}

a $\mathrm{P}<0.05$ compared with control group; ${ }^{\mathrm{P}} \mathrm{P}<0.05$ compared with SAHA group; ${ }^{\mathrm{c}} \mathrm{P}<0.05$ compared with sorafenib group. SAHA, suberoylanilide hydroxamic acid; MMP-2, matrix metalloproteinase-2; MMP-9, matrix metalloproteinase-9; uPA, urokinase type plasminogen activator.

in sorafenib and SAHA+sorafenib groups and MMP-9 protein in SAHA, sorafenib and SAHA+sorafenib groups were significantly decreased, respectively $(\mathrm{P}<0.05)$. In addition, the expression levels of MMP-2, MMP-9 and uPA protein in SAHA+sorafenib group were significantly lower than those in SAHA and sorafenib groups, respectively $(\mathrm{P}<0.05)($ Table $\mathrm{V})$.

\section{DISCUSSION}

HDACIs are a group of small molecular inhibitors that can inhibit the histone deacetylase activity and restore the acetylation of target proteins. HDACIs can reduce the interaction between DNA and histone, thus making the chromatin structure loose, regulating the expression of specific genes, promoting the cell differentiation, and inducing the apoptosis (Groselj et al., 2013). At present, there are more than 800 compounds in the compound library of HDACIs. In animal experiments, HDACIs also show obvious antitumor activities (Ma et al., 2016). SAHA belongs to the second generation of oximetype HDACIs, and it has higher antitumor activities than hexamethylenebisacetamide. The micromolar concentration $(\mathrm{mol} / \mathrm{L})$ of SAHA has strong killing effect on tumor cells (Hui et al., 2012). This study investigated the inhibitory effect of SAHA combined with sorafenib on human HCC HCCLM3 cell xenografts in nude mice. Results showed that, the inhibition rate of tumor in $\mathrm{SAHA}+$ sorafenib group was significantly higher than that in SAHA and sorafenib group, respectively $(\mathrm{P}<0.05)$. This indicates that, compared with single drug, SAHA combined with sorafenib can enhance the inhibitory effect on HCCLM3 cell in vivo.

Mitogen-activated protein kinase (MAPK) is an important transmitter of the signal transduction from cell surface to cell inside. ERK $1 / 2$ is not only the common pathway of cell proliferation and differentiation signal transduction, but also the common pathway for the transmission of multiple signals into the nucleus in fibroblasts (Ramos et al., 2010). The core of MAPK signal transduction pathway is composed of 3 protein kinases including Raf, MEK and ERK. The activated Raf phosphorylates and activates the downstream substrate MEK1/2, which further phosphorylates ERK1/2, resulting in the cell growth, proliferation and differentiation (Steelman et al., 2011). CyclinD1 is an important cell cycle regulatory protein. It specifically binds to the cyclin-dependent kinase, and promotes the conversion of cells from phase $\mathrm{G}$ to $\mathrm{S}$ stage, thus causing the cell proliferation out of control, which leads to the tumor formation (Tu et al., 2016). Results of this study showed that, compared with SAHA and sorafenib group, the expression levels of MEK1/2, p-ERK1/2 and Cyclin D1 protein in SAHA+sorafenib group were significantly decreased, respectively $(\mathrm{P}<0.05)$. This indicates that, the enhanced inhibitory effect of SAHA combined with sorafenib on HCCLM3 cell in vivo may be related with its inhibiting expression of proteins related to tumor cell proliferation.

It is found that $\mathrm{Bcl}-2$ gene is carcinogenic. Bcl-2 can promote the growth of tumor not by promoting cell proliferation but by regulating the occurrence of cell apoptosis (Xu et al., 2014). Bax is a member of the Bcl-2 family. Bax is highly homologous with Bcl-2, but on the contrary, it has the role of inducing apoptosis. Bax can directly bind to the mitochondrial membrane, change the membrane permeability, cause cytochrome $\mathrm{C}$ to release into cytoplasm, and activate the Caspase family, thus causing the apoptosis (Cost et al., 2010). p53 gene has the function of monitoring cell genome integrity, blocking cell proliferation and promoting cell apoptosis. When the cell cycle DNA is damaged at a certain time, p53 starts the related repair mechanism, and if the repair fails, the cell death program is initiated to remove the mutant cells (Gao et al., 2016). In the present study, the expression level of Bcl-2 protein in SAHA+sorafenib group was significantly lower than that in other groups $(\mathrm{P}$ $<0.05)$, and the expression levels of Bax and p53 protein 
in SAHA+sorafenib group were significantly higher than those in other groups, respectively $(\mathrm{P}<0.05)$. This suggests that, SAHA combined with sorafenib is involved in the regulation of apoptosis related protein expressions.

MMPs and uPA are two kinds of protease closely related to invasion and metastasis of tumor cells. MMP9 is the protease with the largest molecular weight in the MMPs family, and it is synthesized by a variety of metastatic tumor cells. MMP-9 can help the tumor cells to break through various barriers by degrading type IV collagen (Candido et al., 2016). MMP-2 is also a member of the MMPs family. As a proenzyme or glycosylated participant, MMP-2 exists in various parts of the body. MMP-2 can degrade the gelatin and type I, IV and V collagen, thus participating in the process of tumor invasion (Hung et al., 2010). uPA is a serine protein hydrolase. It can convert plasminogen to fibrinolytic enzyme, thus hydrolyzing the fibrin and laminin. uPA plays an important role in the process of tumor invasion and metastasis (Gorantla et al., 2011). Results of this study showed that, the expression levels of MMP-2 and MMP-9 and uPA protein in SAHA+sorafenib group were significantly lower than those in SAHA and sorafenib groups, respectively $(\mathrm{P}<0.05)$. This indicates that, SAHA combined with sorafenib can improve the inhibitory effects on the invasion of tumor cells.

\section{CONCLUSION}

Compared with single drug, SAHA combined with sorafenib can enhance the inhibitory effects on HCCLM3 xenografts in nude mice. The mechanism may be related to its enhanced regulation on expressions of tumor proliferation, apoptosis and invasion signal molecules. This study has provided a theoretical and experimental basis for the clinical application of SAHA to treatment of HCC. This study still has some limitations. Firstly, the correlations among different indexes are not investigated. Secondly, there may be other mechanisms about the synergetic enhancement effects of SAHA combined with sorafenib. These need to be further investigated in next studies.

\section{ACKNOWLEDGEMENT}

This work was supported by Natural Science Fund of Jilin Province (No. 20160101164JC).

\section{REFERENCES}

Bao L, Diao H, Dong N, Su X, Wang B, Mo Q, Yu H, Wang X, Chen C. Histone deacetylase inhibitor induces cell apoptosis and cycle arrest in lung cancer cells via mitochondrial injury and p53 up-acetylation. Cell Biol Toxicol. 2016;32(6):469-482.

Bruix J, Reig M, Sherman M. Evidence-based diagnosis, staging, and treatment of patients with hepatocellular carcinoma. Gastroenterology. 2016;150(4):835-853.

Candido S, Abrams SL, Steelman LS, Lertpiriyapong K, Fitzgerald TL, Martelli AM, Cocco L, Montalto G, Cervello M, Polesel J, Libra M, McCubrey JA. Roles of NGAL and MMP9 in the tumor microenvironment and sensitivity to targeted therapy. Biochim Biophys Acta. 2016;1863(3):438-448.

Cost GJ, Freyvert Y, Vafiadis A, Santiago Y, Miller JC, Rebar E, Collingwood TN, Snowden A, Gregory PD. BAK and BAX deletion using zinc-finger nucleases yields apoptosis-resistant CHO cells. Biotechnol Bioeng. 2010;105(2):330-340.

Gao Q, Zhu X, Chen J, Mao C, Zhang L, Xu Z. Upregulation of $\mathrm{P} 53$ promoted $\mathrm{G} 1$ arrest and apoptosis in human umbilical cord vein endothelial cells from preeclampsia. J Hypertens. 2016;34(7):1380-1388.

Gorantla B, Asuthkar S, Rao JS, Patel J, Gondi CS. Suppression of the uPAR-uPA system retards angiogenesis, invasion, and in vivo tumor development in pancreatic cancer cells. Mol Cancer Res. 2011;9(4):377-389.

Groselj B, Sharma NL, FC Hamdy, Kerr M, Kiltie AE. Histone deacetylase inhibitors as radiosensitisers: effects on DNA damage signalling and repair. Brit J Cancer. 2013;108(4):748754.

Hui KF, Ho DN, Tsang CM, Middeldorp JM, Tsao GS, Chiang AK. Activation of lytic cycle of Epstein-Barr virus by suberoylanilide hydroxamic acid leads to apoptosis and tumor growth suppression of nasopharyngeal carcinoma. Int J Cancer. 2012;131(8):1930-1940.

Hung WC, Tseng WL, Shiea J, Chang HC. Skp2 overexpression increases the expression of MMP-2 and MMP-9 and invasion of lung cancer cells. Cancer Lett. 2010;288(2):156-161. 
Koniaris LG, Levi DM, Pedroso FE, Franceschi D, Tzakis AG, Santamaria-Barria JA, Tang J, Anderson M, Misra S, Solomon NL, Jin X, DiPasco PJ, Byrne MM, Zimmers TA. Is surgical resection superior to transplantation in the treatment of hepatocellular carcinoma? Ann Surg. 2011;254(3):527-537; discussion 537-538.

Lee YH, Hsu CY, Hsia CY, Huang YH, Su CW, Lin HC, Loong CC, Chiou YY, Huo TI. Defining the severity of liver dysfunction in patients with hepatocellular carcinoma by the model for end-stage liver disease-derived systems. Dig Liver Dis. 2012;44(10):868-874.

Ma N, Luo Y, Wang Y, Liao C, Ye WC, Jiang S. selective histone deacetylase inhibitors with anticancer activity. Curr Top Med Chem. 2016;16(4):415-426.

Ramos C, Becerril C, Montaño M, García-De-Alba C, Ramírez R, Checa M, Pardo A, Selman M. FGF-1 reverts epithelialmesenchymal transition induced by TGF- $\{$ beta $\} 1$ through MAPK/ERK kinase pathway. Am J Physiol Lung Cell Mol Physiol. 2010;299(2):L222-L231.
Shen L, Orillion A, Pili R. Histone deacetylase inhibitors as immunomodulators in cancer therapeutics. Epigenomics. 2016;8(3):415-428.

Steelman LS, Franklin RA, Abrams SL, Chappell W, KempfCR, Bäsecke J, Stivala F, Donia M, Fagone P, Nicoletti F, Libra M, Ruvolo P, Ruvolo V, Evangelisti C, Martelli AM, McCubrey JA. Roles of the Ras/Raf/MEK/ERK pathway in leukemia therapy. Leukemia. 2011;25(7):1080-1094.

Tu K, Liu Z, Yao B, Xue Y, Xu M, Dou C, Yin G, Wang J. BCL3 promotes the tumor growth of hepatocellular carcinoma by regulating cell proliferation and the cell cycle through cyclin D1. Oncol Rep. 2016;35(4):2382-2390.

Xu XD, Wu XH, Fan YR, Tan B, Quan Z, Luo CL. Exosomederived microRNA-29c induces apoptosis of BIU-87 cells by down regulating BCL-2 and MCL-1. Asian Pac J Cancer Prev. 2014;15(8):3471-3476.

Received for publication on $01^{\text {st }}$ April 2018 Accepted for publication on $03^{\text {rd }}$ September 2018 